\title{
The Power of Process
}

Nathan Richardson

Oklahoma State University
Ironies abound in our academic architectural design studios. They are insightful ironies if we confront them. We often do not, preferring to focus our attention on the architectural magazine, gallery exhibition, and prize-winning portfolio. These venues are necessary for promoting work, but such an argument isn't useful or insightful. It is more important to look beyond the glossy spread and backlit GIF to our actual methods of production. It is here, in the reflective consideration of design process, that the insightful ironies hold deeper potential to shape our work and impact the world around us.

One of the most glaring disconnects I continue to observe in many design studios is the uninspired nature of desk arrangements. I frequently see rows and rows of uniform desks, sized to accommodate full sheets of illustration board and parallel bars, organized around long, narrow, double-loaded, limited access walkways. It is a shockingly rote and stagnant arrangement of workstations for a space that is intended to teach students about the transformational potential of form, space, and architecture. Most of these design studios are awash with natural light, a quality so indispensable it almost renders all other shortcomings acceptable. That said, too many studio arrangements use "in the box" workstations as the place to teach "out of the box" architecture. For example, you could easily transform any late-twentieth century corporate office space into a twenty-first century academic design studio by removing all of the carpet, most of the ceiling tiles, and about half of the cubicle walls. I am among those that want to believe in the transformational potential of architecture. I see academic design studios as one of the best places to explore that potential. But I also want to believe that there is more to the making of design studio than a lot less carpet, ceiling tiles, and cubicle walls.

The arrangement of our studio spaces is just one frequent example of a reality I've often observed; students are remarkably productive not because of the space in which they work, but despite it. Furthermore, students are so objectively busy and productive, that they fail to be sure that their work is taking them toward some proper and useful conclusion. And finally, design students are so active in a process of trial and error, that they fail to properly absorb feedback loops necessary to take their work in new, fresh, and infinitely more valuable directions.

This paper seeks to demonstrate the fallacy of productivity that so often ignites designers and educators. There is a cloud of productivity in design studio education that is simultaneously useful and dangerous. All too often, students and educators set design formation, thinking, review, and presentation on some inalterable trajectory-much like simultaneously setting your Tesla to ludicrous and auto-pilot mode. It leads us (or the machines we control) through nearly endless cycles of repetitive productivity that are only mercifully interrupted by inconvenient deadlines. A bit of introspection can and should affect our work if we are willing. But we have to reconsider our process in a few distinct ways for it to hold any transformative potential for educators, designers, architects, and the lives of people we aim to improve.

There are three distinct ways that process is especially powerful. First, it addresses the steps, activities, and experiences that take us 
toward some objective end. That is, it rightfully elevates the way work is conducted alongside the results of that work. Secondly, process requires that our work take us on an objective path of refinement, advancement, and progress, towards a logical and useful resolution. That is, we are headed to a place that is better than where we started. Third and perhaps most powerfully, process reflects the importance of a series of feedback loops that affect the trajectory of our work. That is, we are open to process new information as we take new steps in advancing our work toward its most potent resolution. In short, the power of process (as explored in this paper) addresses the importance of reconsidering the way we work (our activities) to ensure that our work is moving forward (advancement) by openly leveraging all the appropriate feedback loops at our disposal (awareness).

What follows are three sections that deal with each component of this definition individually. Each section includes a short studio scene that reveals an overlooked aspect of process. The scenes are loosely inspired by actual events. The scenes are followed by specific examples of reconsidered studio activities that further reveal the power of process. The images set alongside this text illustrate non-architectural precedents that are used in studio as students creatively reconsider process design. Among these precedents are Richard Serra's Verb List, James Turrell's Roden Crater, Droog's Do-Hit Chair, and Banksy's Love is in the Bin.

\section{PROCESS AS ACTIVITIES}

Imagine this scene. A student sits down to their drafting desk in a design studio awash in natural light. The subtle buzz and hum of beginning design studio education fills the room. The temperature is a comfortable $72^{\circ}$ Fahrenheit, only disrupted by the unrelenting breeze of the exposed canon diffusers on the ceiling-mounted ductwork. The adjustable drafting desk is set flat, unlikely to ever again reach its peak potential. On that desk, the student observes an architectural drawing from late last night. They need to make it marginally better before their professor arrives for a "desk-crit." They do what they've so often observed and grab a 12" roll of trace paper and a bold sign pen, quickly setting a remarkable volume of ink on layer-after-layer of trace paper, in a sequence of the most indiscernible

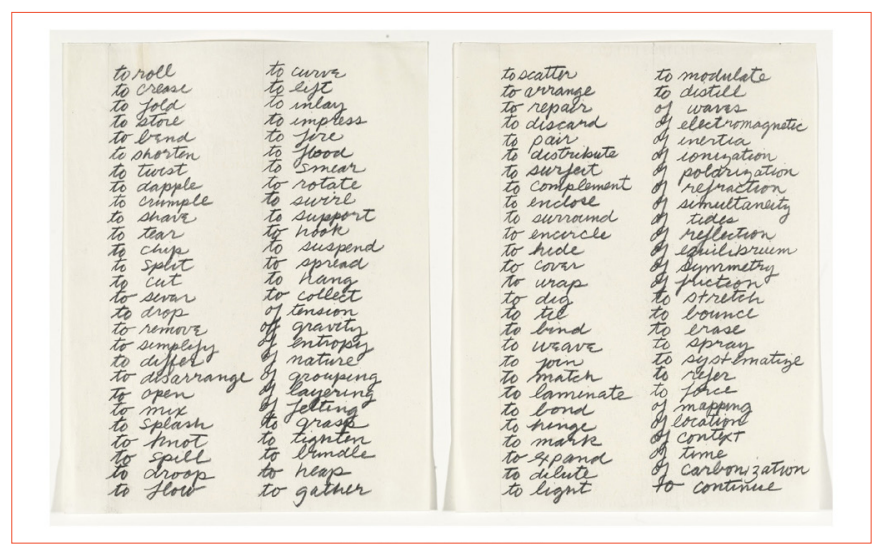

Figure 1. Richard Serra's Verblist was an instrumental part of his process art. ${ }^{1}$ one-line drawings depicting a near infinite number of potential changes to their work. The set of drawings, if it is clear about anything, depicts the utter cloud of confusion that overshadows the students work and their diligent effort to improve it.

The scene I've depicted above is often surrounded by a host of student questions. What do you want for Monday? Should I do models or drawings? What if I don't have time to make a new model? How many perspectives do you want? These are earnest and well-motivated questions. As a professor, I do my best to answer them as constructively as possible. There is a time for straight-forward and simple answers: a model, a drawing, 1/4" =1'-0", etcetera. That said, I also want to enable students to consider and determine for themselves the appropriate manner and method for their work. To that end, I find myself dedicating more and more attention to student assignments in process design. For instance, as a part the urban studio I teach, I frequently dedicate the first phase of each project to a proposal.

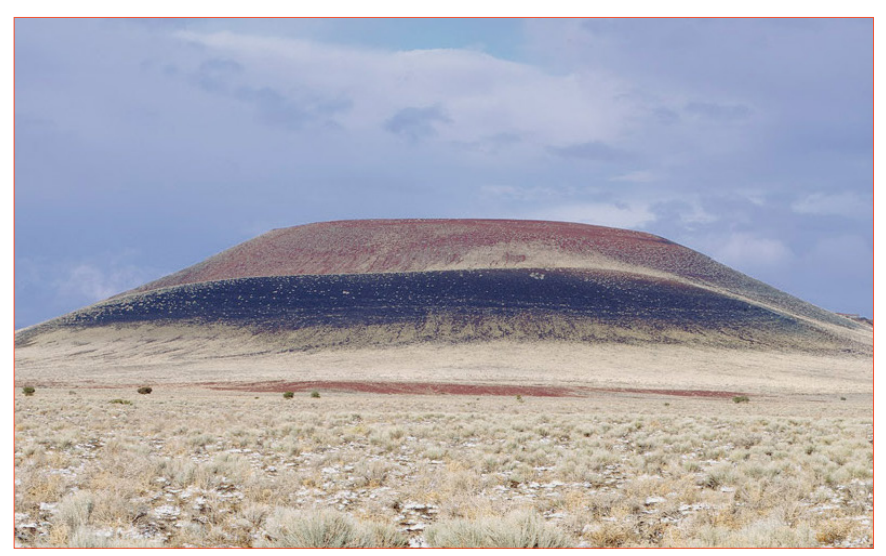

Figure 2. James Turrell's Roden Crater has been ongoing since $1977 .{ }^{2}$

In the proposal phase, student teams are required to articulate the method and manner of their work over the remaining phases of the project. Left alone, students often give me schedules that clearly miss the mark. ("We'll spend one week on schematic design, one week on design development, two weeks on construction documents, and three days on construction administration.") I remind them that we aren't building their project and this isn't an imaginary exercise. I really want them to answer the following questions. When will you work? How long will you work? What will you do? How will you communicate with each other? What deliverables will you produce along the way? What issues will you investigate? What roles and responsibilities will each team member take on and/or share? How will you exhibit your work in the end? How much will it cost? Who will you need to consult along the way? When pressing students for answers to these questions, I've been surprised by two distinct reactions. First, students genuinely struggle to get comfortable with the idea that they are responsible to decide how they conduct their work. Somehow, we've trained them to take direction extremely well, and underprepared 
them to formulate that direction for themselves. Secondly, and more optimistically, I've been surprised by the inventiveness of students when they really turn their attention to process design. They can be very creative designers in that realm, when pressed to do so. In one of my recent urban design studios, we had teams variously decide to write stories, conduct mapping studies with slime mold, and communicate through a host of media: film, print, clay, miniatures, scale models, and full-size replicas. This was primarily because we asked them to actively design their process and required more than pro-forma schedules and activities.

\section{PROCESS AS ADVANCEMENT (PROGRESS)}

Imagine this scene. A teaching assistant sits down to an empty studio desk to grade a recently completed stack of analysis projects. This second year project was quite simple. Students were asked to select and study a well-designed house through a conventional set of drawings by developing a set of exploratory analytical diagrams that reveal the home's most important design lessons. Grading the analysis project was also quite simple. Did the student have the required drawings on paper in the right sequence at the appropriate scale? Did the student sufficiently analyze a range of topics from the circulated list of possibilities? Was the graphic and written information substantive, easy to follow, and useful? This wasn't really a book-binding project-until it was. Deep in the stack of otherwise spiral-bound volumes, was a project unrivaled in girth and weight. This particular student, apparently unsatisfied by the uninspired potential of staples and binder-clips, used the most robust set of architectural materials and hardware known to any bound volume: steel plate, plexiglass, plywood, hex head bolts, and the like. There was only one problem; it could not be opened. The front and back cover were rigid and hingefree, bolted together with a compressive force only necessary in actual structural connections. It was an impenetrable catalogue of student insight.

The scene I've depicted above is a troubling example of something I often confront in design studio education. Students often embrace projects with such excess zeal, that they stray to the point of only solving problems of their own making, or worse, they create so many new problems in formulating a potential solution, that the final project is fundamentally inappropriate for its originally intended purpose. They miss one fundamentally important nature of process. That the end is objectively better than the beginning. That is not to say that the end is perfect, complete, inalterable or anything of the sort. But an effective process should be structured with some useful and intentional end in mind.

I have sought to address this issue in a number of ways. I encourage students to think strategically about where they intend to take the project. What is their agenda? What are their goals? Do they want to build something? Do they want to break something? Do they want to write something? Do they want to convey an idea, concept, form, or building? Do they want to inquire or provoke? Do they want to lead or follow? All of these questions have an impact on where, how, and why the students work on their projects. It is a question of process-but with an end in mind. One exercise l've found helpful in this area are review memos. The review memo is a single page form that I require students to fill out (before a review session) that answers a few key questions about the status of their work. In the memo, I ask them to articulate the following. What have we done since our last review? How satisfied are we with the status of our project (on a range of relevant topics)? What topics do we want to address in the review meeting? What questions would we like answered? What do we plan to prepare for the next meeting? The answers students articulate in these memos are insightful for a number of reasons. First, they come to the review session with a more fully articulated agenda. They are more prepared, focused, and efficient. Second, as a professor, I come to the meeting with a clearer understanding of the students' mindset, expectations, and needs. Third, we have a better collective understanding of where we are in the design process (where are we going and where have we been). In my experience this helps ensure that we are all focused on the most salient aspects of the project and headed toward an acceptable conclusion.

\section{PROCESS AS AWARENESS (FEEDBACK LOOP)}

Imagine this scene. A professor is walking through fifth-year design studio. It is Friday-a great opportunity to review student work prior to the long weekend. There are about five student-teams frantically working to pinup their work for an informal review. The first group has a new digital model, but needs a few more minutes to print out the most salient views. The second group laser-cut an entirely new physical model, but needs another hour to assemble the parts and pieces. The third group has an incredibly large, heavy, and inalterable MDF model, fresh off the CNC router table, but needs a few more hands to get it into position. The fourth group has an artfully assembled site model-no proposal-but beautiful context. The fifth group has everything complete for review, but stumble through their presentation because they have given no thought to how and why they are presenting.

The problems I've depicted in the scene above are sufficiently self-evident. It is still very difficult for students to see and consider

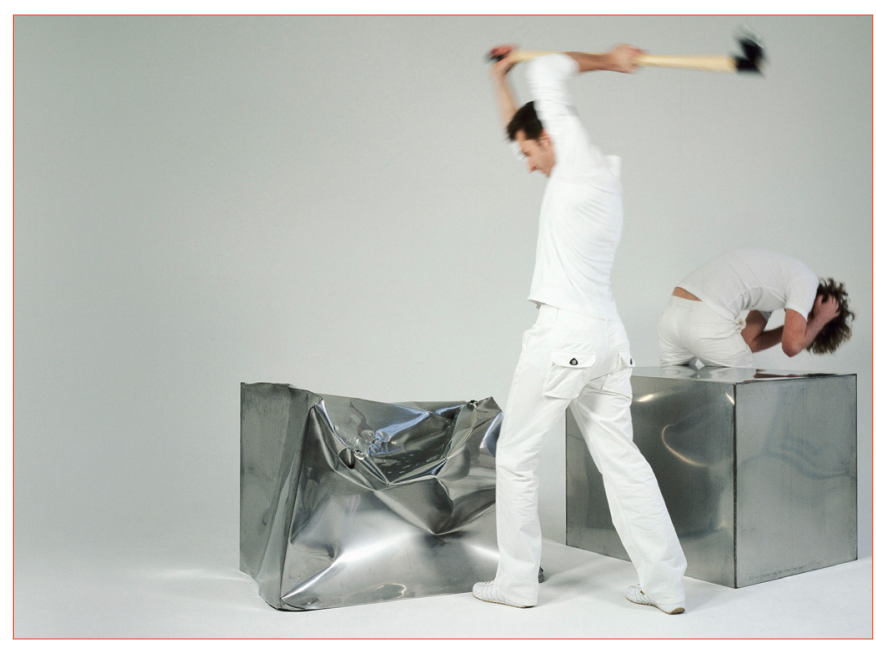

Figure 3. The Do-Hit Chair is finished by the end-user with a mallet. ${ }^{3}$ 
their shortcomings while they are knee deep in them. That said, I've been remarkably surprised by the quality of student feedback, when it is appropriately conditioned and harnessed. The feedback loop is one of the most essential aspects of process. And it is often most effective when the feedback is provided from different sources, in multiple venues, in different formats, at various points along the way. I've recently sought to broaden the spectrum of feedback students are provided. This includes reviewing work at desks, community tables, inside, outside, in studio, in other classroom buildings, at architectural firms, in elevators, on field trips, etcetera. This not only prepares students to be flexible in the setting of their presentations, but shapes the manner in which they receive the feedback. I also seek to vary the source of feedback. Students should gain insight from themselves, their teammates, other students and professors, other professionals, non-professionals, end-users, and beyond. This enhances the quality of the feedback, but also enables them to better converse with non-professors, non-students, and non-architects. Finally, we try to vary the format of the feedback. We can and should provide them feedback in a wide range of media. At various points along the

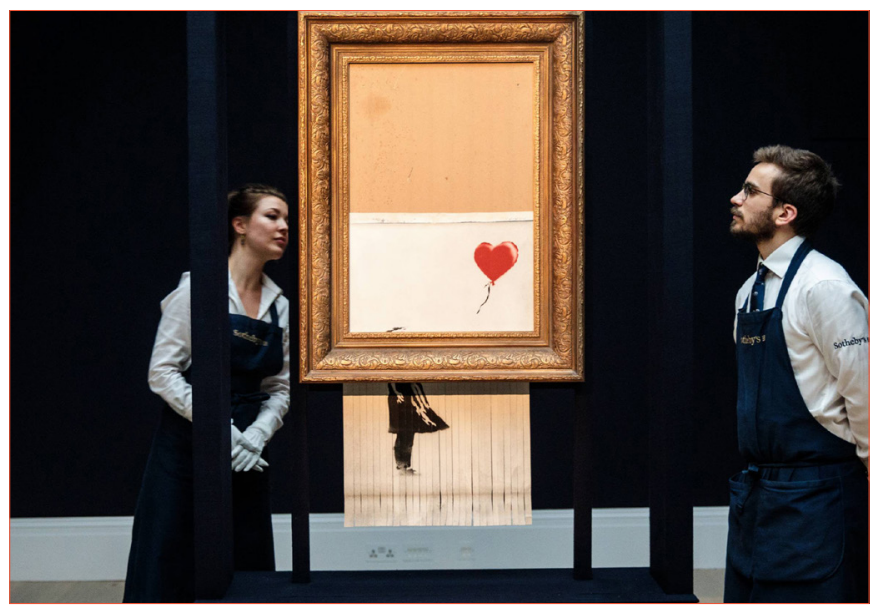

Figure 4. Girl with Red Balloon was shredded immediately post auction at Sotheby's by the artist Banksy, who later renamed the work Love is in the Bin. Image: Jack Taylor/Getty Images. ${ }^{4}$

process, we aim to provide feedback in written, oral, and visual form.

In a recent urban design studio, we held our usual round of interviews in which student teams presented their proposals for the project. We held the interviews in another building on campus in a room the students had never presented in. Students had little prior knowledge of where they would be presenting. We also filmed the student presentations and provided the videos to each team at the conclusion of their interview. In the end, we required each team to write a onepage reflective memo about what they observed in their interview video. The student insights were strikingly similar to the comments shared among the faculty in private. In this instance at least, it was extraordinarily insightful to place the students in an unfamiliar place and have them critique their own presentations. It facilitated a level of self-reflection that was especially on point.

\section{CONCLUSION}

The September 2011 issue of Architect magazine ${ }^{5}$ is illustrated with a cover that is especially noteworthy. The cover features two confident architects, starkly dressed in black and white, standing amidst rubble and ruin in every direction. They are on the scene of some exceptional disaster, astutely prepared to save the day. The message is confidently announced in the lower right-hand corner of the page; "Natural Disasters...Architecture to the Rescue!" The issue's theme is explored in a series of lofty and earnest articles-the summation of which is reasonably clear. Natural disasters are more frequent than ever. Architects and designers are uniquely equipped to help. There are two fantastic illustrations inside the issue. One features architects working feverishly inside a small office with computers, drawings, and a T-square. Another illustration shows a hint of reconstruction with a new building befitted with a sparkle rarely seen outside low-budget toothpaste commercials. A short summary of these illustrations is in order. The city is given new life through newly constructed buildings, designed by architects with computers and T-squares that are (curiously) the only people on scene in a city that was formerly reduced to rubble.

I appreciate what those illustrations reveal about the way the profession of architecture sees itself. It reveals a genuine desire to make a positive impact. But it also reveals an overlooked aspect of making an impact. That is, the power of process. In order to achieve any impact close to the aspirations reflected in the cover, it will take a complete

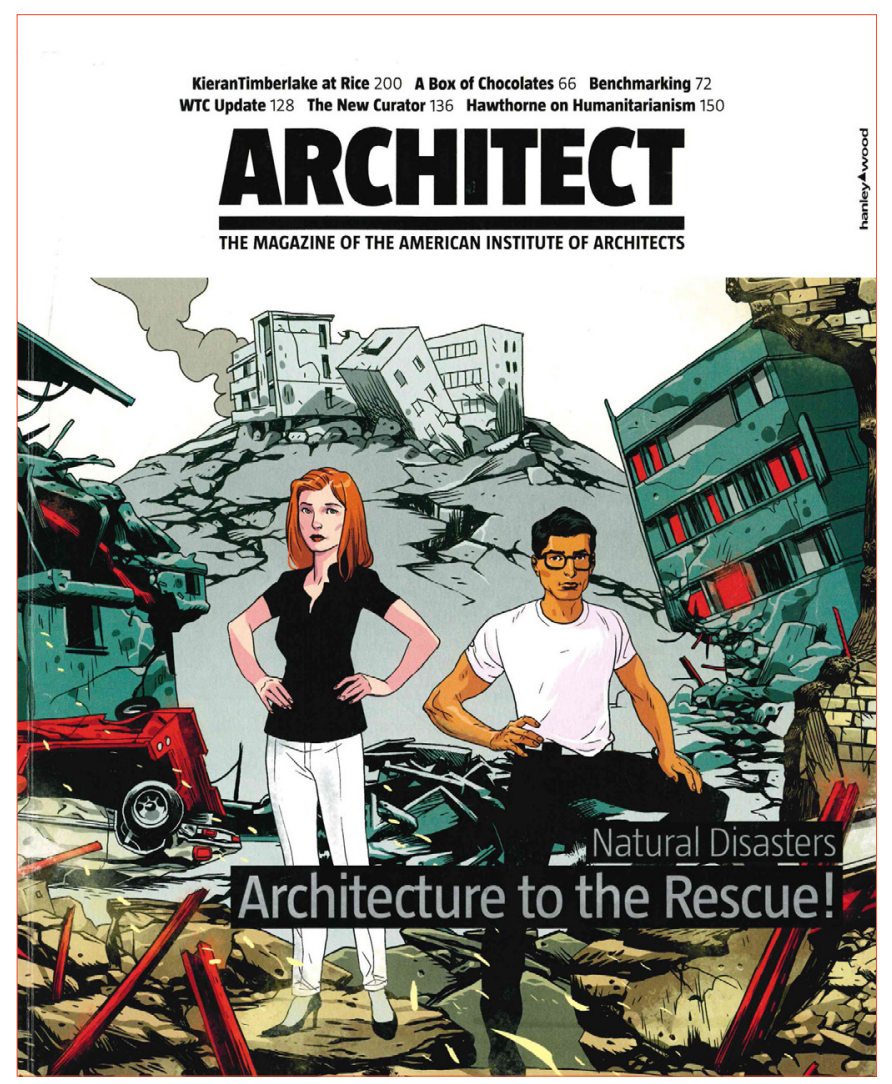

Figure 5. Cover Illustration, Architect Magazine, September 2011.5 
reconsideration of our work. It will take more than T-squares. It will take more than trace paper and a sign pen. It will take more than $\mathrm{CNC}$ routing machines and loads of MDF. It will take more than the most obvious phasing structure (SD, DD, CD, and CA, for example). If the profession of architecture is prepared to address the changing nature of our environmental, economic, and physical conditions, we must be prepared to completely reconsider our process. That is, we must critically reassess the things we do, fully prepared to adapt with new knowledge and insight, relentlessly focused on ensuring our work reaches some constructive and appropriate end. If it is to happen in the profession, it must start in the academic design studio. In order for much good to come from such a change in our design and education methods, it's essential that we loosen our fixation on familiar things and set ourselves adrift for a time. It's one of the primary reasons we so often miss the challenges our world faces; we are too fixated on our classical themes and compositional sanctimony. That's not an easy call for many educators and architects-essential as it is.

\section{Notes}

1. Richard Serra, Verb List, 1967-1968 (The Museum of Modern Art). https://www.moma.org/collection/works/152793

2. James Turrell, Roden Crater, 1977-Present (The Skystone Foundation). http://rodencrater.com/about/

3. Marijn van der Poll, Do Hit Chair, 2000 (Droog Design). https://www.droog.com/webshop/product/ do-hit-chair-hit-van-der-poll

4. Banksy, Love is in the Bin, 2018. See also, Juliete Helmke, "Is Banksy Trying to Orchestrate His Own Unmasking," (Observer, December 26, 2018). https://observer.com/2018/12/ was-banksy-revealing-identity-with-sothebys-stunt/

5. Architect Magazine, September 2011 (Hanley Wood). 